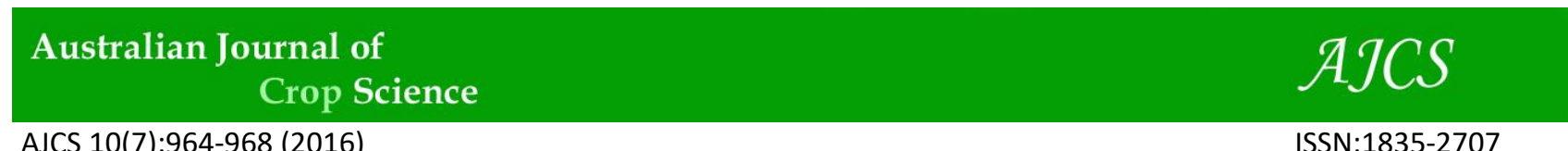

AJCS 10(7):964-968 (2016)

ISSN:1835-2707

DOI: 10.21475/ajcs.2016.10.07.p7623

\title{
A direct organogenesis protocol from shoot segments of Solanum tuberosum cv. Monalisa
}

\author{
Nádia Alves Campos ${ }^{1}$, Glacy Jaqueline da Silva ${ }^{2}$, Márcia Fabiana Barbosa de Paula ${ }^{3}$, Thaís Barros \\ Rodrigues $^{4}$, Leonardo Augusto Zebral Rodrigues ${ }^{5}$, Luciano Vilela Paiva ${ }^{5}$
}

\author{
${ }^{1}$ Biosystems Department, KULeuven, Leuven, Belgium \\ ${ }^{2}$ Molecular Biology Department, Paranaense University, Umuarama, Brazil \\ ${ }^{3}$ Genetics and Biotechnology Department, Santa Cruz State University, Ilheus, Brazil \\ ${ }^{4}$ Nuclear Energy Center in Agriculture, São Paulo University, Piracicaba, Brazil \\ ${ }^{5}$ Chemistry Department, Lavras Federal University, Lavras, Brazil
}

\section{*Corresponding Author: nadialvesnep@hotmail.com}

\begin{abstract}
Transgenic technology is an excellent alternative for improvement of crop production and disease free crops such as potato, which is one of the most important crops worldwide. One of the first steps to apply the transgenic technique is the establishment of an efficient plant regeneration protocol. This is a limiting step in this kind of study, since most protocols are species-specific and some of them do not adequately respond to in vitro culture or present low regeneration rates. The objective of this study was to stablish an efficient regeneration protocol of Solanum tuberosum $\mathrm{cv}$. Monalisa from internodes explants. This work is important since most in vitro protocols are based on shoots. Twenty five treatments were performed, with each treatment being composed of six internodes in flasks containing MS medium supplemented with a fixed concentration of zeatin riboside $\left(3 \mathrm{mg} . \mathrm{L}^{-1}\right)$ (ZEA), varying concentrations of naphthaleneacetic acid ( 0 to $1 \mathrm{mg}$. $\left.\mathrm{L}^{-1}\right)$ (NAA), and gibberellic acid $\left(0\right.$ to $\left.3 \mathrm{mg} . \mathrm{L}^{-1}\right)\left(\mathrm{GA}_{3}\right)$. The treatment composed of ZEA, 0.05 mg. $\mathrm{L}^{-1}$ of NAA, and $0.10 \mathrm{mg} . \mathrm{L}^{-1}$ of $\mathrm{GA}_{3}$ was considered the best for shoot regeneration from potato internodes. The study was able to establish a specific regeneration protocol for Monalisa cultivar. This result can be very useful since it is possible to obtain plants from internode, without the requirement of meristematic regions, enabling the obtainment of a higher number of plants.
\end{abstract}

Keywords: Regeneration, Potato, Biotechnology, Genetically Modified Organism, Tissue culture and Solanum tuberosum. Abbreviations: MS _ Murashige and Skoog medium, ZEA _ zeatin riboside, NAA _ naphthaleneacetic acid, GA ${ }_{3}$ - gibberellic acid, IAA _ 3-indol-acetic acid.

\section{Introduction}

The origin potato center (Solanum tuberosum L.) is located in the South America Andean region. This tubercle was introduced in Europe in the sixteenth century, and subsequently to all other continents (Love et al., 2003). Currently, it is considered the fourth food source in consumption worldwide, losing only for maize, rice, and wheat (FAO, 2013). Cultivated in more than 125 countries, the 2013 world's production was equivalent to 376.5 million tons, in an area of 19.3 million hectares. Brazil represents $1 \%$ of this production, with an average of approximately $27 \mathrm{Hg}$ $\mathrm{ha}^{-1}$ in 2013 (FAO, 2013). One of the limiting factors for potato production is a high susceptibility to diseases, specially viruses, such as the potato $\mathrm{Y}$ virus, which alone could cause productivity losses of about $50 \%$ (Rezende et al., 2013; Goyer et al., 2015). The development of resistant cultivars by conventional breeding is not an easy task, since current cultivars have a narrow genetic basis due to the development from a few South America germoplasm banks. Furthermore, potato grows from vegetative propagation, having high heterozygous sensitivity rate and endogamic depression (Barrel et al., 2013). New knowledge acquired after complete potato genome sequencing (TPGSC, 2011) opened a range of possibilities to genetic manipulation, specially through genetic transformation due to the high potato susceptibility to Agrobacterium tumefaciens infection
(Vayda and Belknap, 1992). Recombinant DNA technology and plant regeneration from tissue culture have been successfully employed to introduce exogenous genes into an agricultural plant of interest, besides allowing better understanding regarding the role of different genes and metabolic pathways (Vayda and Belknap, 1992; Torres et al., 2000; Romano et al., 2001; Homrich et al, 2012). Regeneration of feasible plantlets is a limiting step of genetic transformation protocols and most of the tissue culture process is highly genotype dependent. It is then required to establish a specific protocol for each genotype under study (Pereira and Fortes, 2003; Sahoo et al., 2011; Ghobeishavi et al., 2015). Thus, some variables such as culture medium, type and concentration of hormones and antibiotics, explants type and size, and in vitro culture time conditions, should be taken into consideration in order to achieve an efficient genetic transformation protocol (Rezende et al., 2013). The Monalisa cultivar originated in Holland is widely employed due to consumer demands, and it is ideal for frying and baking (NPCF, 2015). Therefore, this cultivar becomes an ideal candidate for genetic transformation studies. In vitro vegetative propagation via organogenesis may occur directly or indirectly. In direct organogenesis, different kinds of explants such as leaves, shoots, stems or roots are used to induce the formation of new plants directly from the explant. 
In indirect organogenesis, explants are first dedifferentiated into callus, which consist of totipotent and non-organized cells, that first regenerate in the shoot and afterwards in a new plant (Ovecka, $\mathrm{M}$ et al., 2000; Cai, $\mathrm{Z}$ et al., 2015; Du, L et al., 2015). Direct organogenesis usually regenerates a small number of seedlings (Pedraza-Santos et al., 2006), making the process laborious, but it has a lower rate of somaclonal variation as an advantage (Detrez, C et al., 1989; Kesari, V et al., 2012). Indirect organogenesis has a great potential to generate a large number of calli, and with it, a higher chance of regenerating seedlings (Thorpe and Bondi, 1991). However, by going through the callus formation process, it is possible in some cases to have the appearance of somaclonal variation (Soniya et al., 2001; Shen et al., 2007). Thus, the objective of this study was to stablish an efficient regeneration protocol for Monalisa cultivar, through direct and indirect organogenesis from internodes. A protocol without the requirement of meristematic regions can facilitate its later employment in genetic transformation processes, considering that it can regenerate a higher number of plants through this technique.

\section{Results and Discussion}

Different results were obtained from treatments of non organogenic callus and complete regenerated plants.

\section{Formation of non organogenic calli}

The majority of treatments analyzed (identified as $1,2,5,6$, $7,9,10,11,14,15,16,17,19,20,21,22,23,24$, and 25), merely showed a big non organogenic calli formation (calli that do not have meristematic centers and consequently are unable to regenerate plants) (Figure 1). Because of these results, the statistical analysis applied to these treatments did not point out any significance, proving that such treatments were considered inappropriate for Monalisa cultivar regeneration.

\section{Plant regeneration}

Different results were found in the $3,4,8,12,13$, and 18 treatments, which presented shoot formation (Figure 1). The Tukey Test statistical analysis showed a significant difference $(\mathrm{p} \leq 0.05)$. Treatments $3,4,8$, and 18 presented indirect organogenesis plantlets regeneration, and treatments 12 and 13 presented plantlets regenerated through direct organogenesis. In treatments 12 and $13,0.1 \mathrm{mg} \mathrm{L}^{-1}$ of $\mathrm{GA}_{3}$ was used in combination with low ANA concentration. Other treatments with the same $\mathrm{GA}_{3}$ concentration, but with high or no ANA concentration, did not present any significant difference, showing that the combination of low ANA and $\mathrm{GA}_{3}$ concentration have a large potential to generate direct organogenic plantlets in Monalisa cultivar.

Composition of the medium employed in these treatments and the average explant number per treatment are specified in Figure 2. A large advantage found in the treatments 12 and 13 was that both of them had more plantlets generated when compared to other treatments, since they regenerate plantlets through direct organogenesis. Qualitatively, treatment 12 was observed to have higher shoots, some more big leaves and pronounced roots, when compared with treatment 13 . Therefore, treatment 12 was considered a better treatment for shoot regeneration through direct organogenesis (Figure 1). Results were consistent with previous studies performed with other potato cultivars. Rezende et al., 2013, conducted an indirect organogenesis study using potato shoot $c v$. Atlantic, wherein, from combination of zeatin, IAA (3-indol-acetic acid) and NAA, regeneration protocols were established for in vitro cultivation. Torres et al., 2000, whom studied $c v$. Achat, achieved success in regeneration using basic MS medium supplemented with zeatin at a $5.00 \mathrm{mg} \mathrm{L}^{-1}$ concentration and rooting using $0.05 \mathrm{mg} \mathrm{L}^{-1}$ of NAA. A similar result was found again by Torres et al., 2003, whom worked with Baronesa and Macaca $c v$, and managed to regenerate whole plants using MS supplemented with 0.05 $\mathrm{mg} \mathrm{L}^{-1}$ of IAA, $3.00 \mathrm{mg} \mathrm{L}^{-1}$ of $\mathrm{GA}_{3}$, and $3.00 \mathrm{mg} \mathrm{L}^{-1}$ of zeatin, besides other salts and vitamins. However, as an advantage of the current research, the authors demonstrated the possibility to regenerate potato plants with lower zeatin concentration $\left(3.00 \mathrm{mg} \mathrm{L} \mathrm{L}^{-1}\right)$, thus decreasing costs. Furthermore, it is proved that it is possible to directly regenerate potato seedlings from a nodal explant without the requirement of a specific culture medium for callus formation, which reduces the possibility of somaclonal variation and avoids major problems in external contamination by decreasing manipulation of plant material.

These results demonstrate again that in vitro plant regeneration process is extremely cultivar dependent, requiring the establishment of a specific protocol for each cultivar under study.

Studies with other species were already presented, as in Picoli and Otoni, 2001, whom induced embryogenesis, callus and root formation from eggplant (Solanum melongena L.) after a day of contact between the cotyledon and the MS medium supplemented with $5 \mathrm{mg} \mathrm{L}^{-1}$ of NAA. They showed that concentration and time required for tissue differentiation greatly varies within different species, and even within the same family.

This study showed an extremely important result for employment in plant molecular biology, aiming at the genetic potato transformation, in order to maintain or even enhance its socioeconomic characteristics as widespread and varied. Establishment of an efficient regeneration protocol for in vitro potato cultivation is deeply relevant for potato breeding programs, due to the importance of the culture worldwide and the potential of genetic gains from new available technologies, such as genetic transformation. Taking this into consideration, it was possible to successfully establish a direct organogenesis regeneration protocol for the Monalisa cultivar in MS medium, supplemented with $0.05 \mathrm{mg} \mathrm{L}^{-1}$ and $0.10 \mathrm{mg} \mathrm{L}^{-1}$ of NAA, $0.10 \mathrm{mg} \mathrm{L}^{-1}$ of $\mathrm{GA}_{3}$, and $3.00 \mathrm{mg} \mathrm{L}^{-1}$ of zeatin.

\section{Materials and Methods}

\section{Source of explants}

Potato (Solanun tuberosum) Monalisa cultivar grown in vitro were provided by the Multi-Plant Technology Plant - LTDA company, based in Andradas/Brazil. These plants were kept inside a growth chamber with 16 photoperiod hours, $26{ }^{\circ} \mathrm{C}$ and $50 \mu \mathrm{mol} \cdot \mathrm{m}^{-2} \cdot \mathrm{s}^{-1}$ luminous intensity, cultivated at every 30 days in MS medium (Murashige and Skoog, 1962) without hormone supplementation, with $3 \%$ sucrose added, $\mathrm{pH} 5.7 \pm$ 0.1 , before being autoclaved and gelled with $0.6 \%$ agar. In a laminar flow chamber, these plants were used as a source of explants which were defined as internodes with standardized size from 6 to $10 \mathrm{~mm}$, and without buds.

\section{Organogenesis}

For organogenesis tests, the MS medium was used with the same concentrations of sucrose and agar mentioned above. 25 
Table 1. Average number of explants that formed shoots for positive treatment of regeneration. Tukey test at $0.05 \%$. Average followed by the same letter do not differ.

\begin{tabular}{lccc}
\hline Treatment & ANA $\left(\mathrm{mg} / \mathrm{L}^{-1}\right)$ & $\mathrm{GA}_{3}\left(\mathrm{mg} / \mathrm{L}^{-1}\right)$ & Average number of explants \\
\hline T3 & 0.01 & 0.00 & $0.33^{\mathrm{C}}$ \\
T4 & 0.50 & 0.00 & $0.66^{\mathrm{C}}$ \\
T8 & 0.10 & 0.05 & $1.00^{\mathrm{B}}$ \\
T12 & 0.05 & 0.10 & $6.00^{\mathrm{A}}$ \\
T13 & 0.10 & 0.10 & $6.00^{\mathrm{A}}$ \\
T18 & 0.10 & 2.00 & $0.33^{\mathrm{C}}$ \\
\hline
\end{tabular}

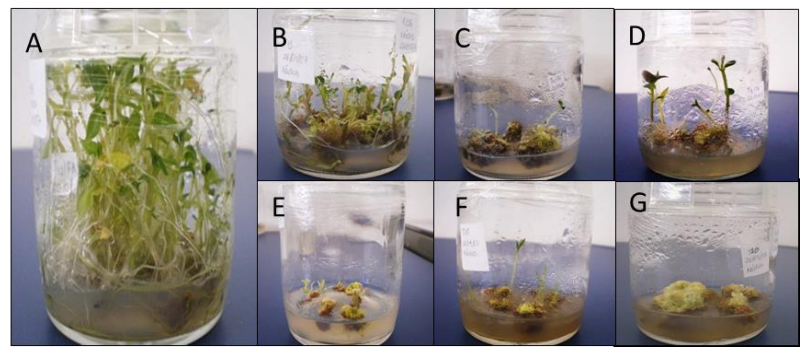

Fig 1. Non organogenic calli formation and internode plant regeneration after 60 days in MS medium. Each figure indicates a treatment, highlighting the best treatment to regenerate shoots: A (T12), B (T13), C (T4), D (T8), E (T3), F (T18), G (T20) respectively. Pictures A and B show direct organogenesis regeneration; C, D and F show indirect organogenesis regeneration and picture $\mathrm{G}$ show non organogenic callus formation.

Table 2. Treatment descriptions obtained by the differential combination of Zeatin, NAA and $\mathrm{GA}_{3}$ in MS medium, for cv. Monalisa regeneration.

\begin{tabular}{lccc}
\hline Treatment & Zeatin $\left(\mathrm{mgL}^{-1}\right)$ & NAA $\left(\mathrm{mgL}^{-1}\right)$ & $\mathrm{GA}_{3}\left(\mathrm{mgL}^{-1}\right)$ \\
\hline T1 & 3.00 & 0.00 & 0.00 \\
T2 & 3.00 & 0.05 & 0.00 \\
T3 & 3.00 & 0.10 & 0.00 \\
T4 & 3.00 & 0.50 & 0.00 \\
T5 & 3.00 & 1.00 & 0.00 \\
T6 & 3.00 & 0.00 & 0.05 \\
T7 & 3.00 & 0.05 & 0.05 \\
T8 & 3.00 & 0.10 & 0.05 \\
T9 & 3.00 & 0.50 & 0.05 \\
T10 & 3.00 & 1.00 & 0.05 \\
T11 & 3.00 & 0.00 & 0.10 \\
T12 & 3.00 & 0.05 & 0.10 \\
T13 & 3.00 & 0.10 & 0.10 \\
T14 & 3.00 & 0.50 & 0.10 \\
T15 & 3.00 & 1.00 & 0.10 \\
T16 & 3.00 & 0.00 & 2.00 \\
T17 & 3.00 & 0.10 & 2.00 \\
T18 & 3.00 & 0.50 & 2.00 \\
T19 & 3.00 & 1.00 & 2.00 \\
T20 & 3.00 & 0.00 & 2.00 \\
T21 & 3.00 & 0.05 & 3.00 \\
T22 & 3.00 & 0.10 & 3.00 \\
T23 & 3.00 & 0.50 & 3.00 \\
T24 & 3.00 & 1.00 & 3.00 \\
T25 & 3.00 & & 3.00 \\
\hline
\end{tabular}

Shoot formation

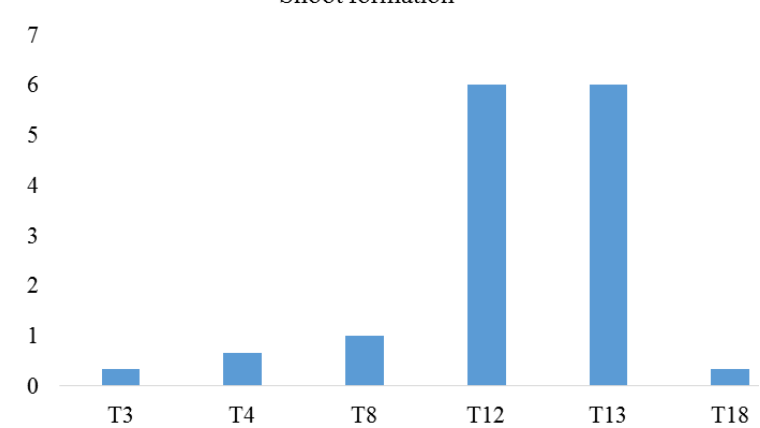

Fig 2. Average number of explants that formed shoots for positive treatment of regeneration. Tukey test at $0.05 \%$. 
treatments were defined, in which the zeatin concentration was fixed, combined with naphthalene acetic acid (NAA), and gibberellic acid $\left(\mathrm{GA}_{3}\right)$ in different concentrations (Table 2). Explants were horizontally cultured into flasks containing $40 \mathrm{ml}$ of medium. All treatments were kept in the growth room with a photoperiod of $16 \mathrm{~h}$, temperature of $24 \pm 2{ }^{\circ} \mathrm{C}$, and $50 \mu \mathrm{mol} . \mathrm{m}^{2} \cdot \mathrm{s}^{-1}$ of light intensity. Explants were transferred at every 15 days to a fresh medium until 60 days of cultivation were completed. At this stage, shoot formation was evaluated for each treatment.

\section{Statistical analysis}

The experimental design was completely randomized with three replicates for each treatment. Each flask containing six explants was considered as a replicate. After 60 cultivation days the percentage of explants that regenerated seedlings was evaluated in each treatment, and the averages were compared through the Tukey Test at $5 \%$ probability by the Sisvar software (Ferreira, 2011).

\section{Conclusion and final consideration}

This study was able to successfully establish a direct organogenesis regeneration protocol for the cultivar Monalisa in MS medium, supplemented with $0.05 \mathrm{mg} \mathrm{L}^{-1}$ and $0.10 \mathrm{mg}$ $\mathrm{L}^{-1}$ of ANA, $0.10 \mathrm{mg} \mathrm{L}^{-1}$ of $\mathrm{GA}_{3}$, and $3.00 \mathrm{mg} \mathrm{L}^{-1}$ of zeatin. It is highly relevant for regeneration protocols to consider issues such as cost, reliability, and accuracy. An organogenesis protocol that requires small hormone amounts and that does not have to go through the callogenesis process meets those requirements.

\section{Acknowledgements}

The authors are grateful to the Multi-Plant Technology Plant - LTDA for providing plantlets, and to CNPq, CAPES, and FAPEMIG for grant funding and scholarships.

\section{References}

Barrell JP, Meiyalaghan S, Jacobs JME, Conner AJ (2013) Applications of biotechnology and genomics in potato improvement. Plant Biotech J. 11:907-920.

Cai Z, Jing X, Tian X, Jiang J, Liu F, Wang X (2015) Direct and indirect in vitro plant regeneration and the effect of brassinolide on callus differentiation of Populus euphratica Oliv. S Afr J Bot. 97:143-148.

Detrez C, Sangwan RS, Sangwan-Norreel BS (1989) Phenotypic and karyotypic status of Beta vulgaris plants regenerated from direct organogenesis in petiole culture. Theor Appl Genet. 77:462-468.

Du L, Li Y, Yao Y, Zhang L (2015) An efficient protocol for plantlet regeneration via direct organogenesis by using nodal segments from embryo-cultured seedlings of Cinnamomum camphora L. Plos One. 10:1-10.

Fao, Food and agriculture organization. http://www.fao.org/crop/statistics.html. Acessed $06 \mathrm{Jul}$ 2015.

Ferreira DF (2011) Sisvar: a computer statistical analysis system. Cienc Agrotec. 35: 1039-1042.

Ghobeishavi H, Uliaie ED, Alavikia SS, Valizadeh M (2015) Study of factors influencing somatic embryogenesis in rice (Oryza sativa L.). Int J Adv Biol Biom Res. 3:43-50.
Goyer A, Hamlin L, Crosslin JM, Buchanan A, Chang JH (2015) RNA-seq analysis of resistant and susceptible potato varieties during the early stages of potato virus $Y$ infection. BMC Genomics. 16:472-485.

Homrich MS, Wiebke-Strohm B, Weber RKM, Zanettini MHB (2012) Soybean genetic transformation: a valuable tool for the functional study of genes and the production of agronomically improved plants. Genet Mol Biol. 35:9981010.

Kesari V, Ramesh AM, Rangan L (2012) High frequency direct organogenesis and evaluation of genetic stability for in vitro regenerated Pongamia pinnata, a valuable biodiesel plant. Biomass Bioenerg. 44:23-32.

Love SL, Stark JC, Guenthner F (2003) The origin of potato production systems. In: Starc JC, Love SL (ed) Potato production system, 1st edn. Idaho University, Moscow.

Murashige T, Skoog F (1962) A revised medium for rapid growth and bioassays with tobacco tissue cultures. Physiol Plant. 15:473-497.

NPCF: Netherlands potato consulative foundation. http://www.potato.nl/uk/about_potatoes/variety_catalogue/r as?frm_variety=83. Acessed $06 \mathrm{Jul} 2015$.

Ovecka M, Bobak M, Sarna J (2000) A comparative structural analysis of direct and indirect shoot regeneration of Papaver somniferum L. in vitro. J Plant Physiol. 157: 3281-3289.

Pedraza-Santos ME, Peralta MCLP, Hernandez VAG, Clark EM, Garcia PS (2006) In vitro regeneration of Alstroemeria cv. 'Yellow King' by direct organogenesis. Plant Cell Tiss Org. 84:189-198.

Pereira JES, Fortes GRL (2003) Protocolo para a produção de material propagativo de batata em meio líquido. Pesqui Agropec Bras. 38:1035-1043.

Picoli EA, Otoni WC (2001) Morfogênese in vitro em berinjela influenciada por higromicina e e períodos de exposição em ANA. Cienc Agrotec. 25:1474-1481.

Rezende RKS, Pasqual M, Paiva LV, Paiva R, Masetto TE (2013) Organogênese in vitro de batata (Solanum tuberosum L.) cultivar atlantic visando transformação genética. Semina. 34:1055-1064.

Romano E, Ferreira AT, Dusi AN, Prite K, Avila AC, Nishijima M, Nascimento AS, Bravo FA, Mentaberry A, Monte D, Campos MA, Melo PE, Cattony MK, Torres AC (2001) Extreme resistance to two brazilian strains of potato virus $\mathrm{Y}(\mathrm{PVY})$ in transgenic potato, cv. Achat, expressing the $\mathrm{PVY}^{\circ}$ coat protein. Hortic Bras. 19:118-122.

Sahoo KK, Tripathi AK, Pareek A, Sopory SK, SinglaPareek SL (2011) An improved protocol for efficient transformation and regeneration of diverse indica rice cultivars. Plant Methods. 7:49-60.

Shen X, Chen J, Kane ME, Henny RJ (2007) Assessment of somaclonal variation in Dieffenbachia plants regenerated through indirect shoot organogenesis. Plant Cell Tiss Org. 91:21-27.

Soniya EV, Banerjee NS, Das MR (2001) Genetic analysis of somaclonal variation among callus-derived plants of tomato. Curr Sci. 80:1213-1215.

The Potato Genome Sequencing Consortium (2011) Genome sequence and analysis of the tuber crop potato. Nature. 475:189-195.

Thorpe TA, Harry IS, Kumar PP (1991) Application of micropropagation to forestry. In: Debergh PC, Zimmerman RH (Ed) Micropropagation technology and application, 1st edn. Springer, Netherlands. 
Torres AC, Ferreira AT, Romano E, Cattony MK, Nascimento AS (2000) Transformação genética de batata cultivar Achat via Agrobacterium tumefaciens. Hortic Bras. 18:41-45.

Torres AC, Ferreira AT, Widholzer CFN, Romano E, Peters JA (2003) Expressão eficiente do gene repórter $\beta$ glucuronidase nos tecidos vasculares de batata (Solanum tuberosum L.) utilizando de um promotor específico $\left(\mathrm{BRA}_{3}\right)$ de Agrobacterium rhizogenes. Hortic Bras. 21:176-179.

Vayda ME, Belnap WR (1992) The emergence of transgenic potatoes as commercial products and tools for basic science. Transgenic Res. 1:149-163 